\title{
Comparison of nanofluid heat transfer properties with theory using generalized property relations for EG-water mixture
}

\author{
Seshu Kumar Vandrangi ${ }^{1, \mathrm{a})}$, Suhaimi bin Hassan ${ }^{1, \mathrm{~b})}$ Sharma K.V. ${ }^{2, \mathrm{c})}$, and Prasad Reddy,d) \\ ${ }^{1}$ Department of Mechanical Engineering, Universiti Teknologi PETRONAS 32610 Tronoh, Malaysia \\ ${ }^{2}$ Department of Mechanical Engineering, JNTU Hyderabad, India \\ ${ }^{3}$ Department of Chemical Engineering, Universiti Teknologi BRUNEI
}

\begin{abstract}
A numerical analysis for the determination for turbulent characteristics of fluid flow and heat transfer have been developed by employing the eddy diffusivity equation of Van Driest. The properties of Silicon dioxide $\left(\mathrm{SiO}_{2}\right)$ nanofluid with spherical particles in base liquid ethylene glycol (EG) -water (W) mixture of 60:40 ratio is employed for a wide range of concentrations and bulk temperature. A good agreement of the numerical results with the experimental data for properties and heat transfer is observed. A comparison of Copper oxide (CuO), Aluminum dioxide $\left(\mathrm{Al}_{2} \mathrm{O}_{3}\right)$ and Silicon dioxide $\left(\mathrm{SiO}_{2}\right)$ nanofluids revealed that $\mathrm{SiO}_{2}$ attain higher temperature gradients in comparison to $\mathrm{CuO}$ nanofluid at the same concentration and temperature.
\end{abstract}

\section{Introduction}

Studies using conventional heat transfer fluids such as water, ethylene glycol (EG) and engine oil are subjected to system alterations to meet the desired performance requirements. The methods of augmentation include the use of additives with micron size metal particles dispersed in the liquid $[1,2]$ are quite outdated. Moreover, the size of these particles for heat transfer enhancement proved to be undesirable, due to problems associated with clogging, sedimentation, erosion of pipe lines and large pressure drop. In order to meet the requirements of greater heat transfer rates, the application of nanotechnology has been employed successfully.

Nanofluids are formed by the dispersion of small quantities of nanometer size metal and metal oxide particles in base liquids such as water or ethylene glycol proved to possess higher values of thermal conductivity compared to base liquid. Recent trends suggest that using nanofluids dispersed in EG and water mixture as base liquid has proved to be beneficial for low temperature applications. Experiments undertaken with nanoparticles dispersed in EGwater mixture as base fluid in different ratios seems to be encouraging.

* Corresponding author: suhaimiha@utp.edu.my 
Vajjha et al. [3-5] have conducted various experiments to determine the properties of $\mathrm{Al}_{2} \mathrm{O}_{3}, \mathrm{CuO}, \mathrm{SiO}_{2}$ and $\mathrm{ZnO}$ nanofluids. Praveen et al. [6] determined the rheological properties of $\mathrm{CuO}$ nanofluids. Sundar et al. [7] reported enhanced thermal properties of nanodiamond nanofluids. Sahoo et al. [8,9] carried out experiments with $\mathrm{SiO}_{2}$ and $\mathrm{Al}_{2} \mathrm{O}_{3}$ nanofluids to determine the thermal conductivity and viscosity. Kulkarni et al. [10] performed experiments for the estimation of viscosity with $\mathrm{SiO}_{2}$ nanofluid.

Experiments for the determination of nanofluid forced convection heat transfer coefficients in the turbulent range are undertaken with $\mathrm{Al}_{2} \mathrm{O}_{3}(45 \mathrm{~nm}), \mathrm{CuO}(29 \mathrm{~nm})$, and $\mathrm{SiO}_{2}$ $(20,50,100 \mathrm{~nm})$ for a maximum concentration of $10.0 \%$ for temperature varying from 20 $90^{\circ} \mathrm{C}$ by Vajjha and Das [11] in base liquid EG-water mixture in 60:40 ratio. They have reported an enhancement of $81.74 \%$ in heat transfer for $\mathrm{Al}_{2} \mathrm{O}_{3}$ nanofluid at a concentration of $10 \%$. The pressure loss is reported to increase with volume concentration of the nanofluid. The increase of pressure loss for a $10 \% \mathrm{Al}_{2} \mathrm{O}_{3}$ nanofluid at a Reynolds number of 6700 is about 4.7 times that of the base fluid. The authors developed equations for the nanofluid properties and the Nusselt number. Kulkarni et al. [10] undertook experiments to estimate the convective heat transfer and pressure loss of $\mathrm{SiO}_{2}(20,50,100 \mathrm{~nm})$ nanofluids dispersed in EG-water mixture for volume concentration in the range of $0-10 \%$ with temperatures varying between $20-90^{\circ} \mathrm{C}$. They have reported an enhancement of $16 \%$ in heat transfer coefficient at a concentration of $10.0 \%$ with $20 \mathrm{~nm}$ particle size at $\mathrm{Re}=10000$.

Theoretical analysis for turbulent flow has been modeled by Sarma et al. [12] who introduced a correction factor for the mixing length. Expressions for eddy diffusivity of momentum $\left(\varepsilon_{\mathrm{nf}} / \vartheta_{\mathrm{nf}}\right)$ and heat $\left(\varepsilon_{\mathrm{H}} / \alpha_{\mathrm{nf}}\right)$ have been proposed, where $\varepsilon_{\mathrm{nf}}$ is momentum eddy diffusivity $\left(\mathrm{m}^{2} / \mathrm{s}\right)$ of nanofluid, $\varepsilon_{\mathrm{H}}$ is thermal eddy diffusivity $\left(\mathrm{m}^{2} / \mathrm{s}\right), \alpha_{\mathrm{nf}}$ is thermal diffusivity $\left(\mathrm{m}^{2} / \mathrm{s}\right)$ of nanofluid and $\vartheta_{\mathrm{nf}}$ is kinematic viscosity $\left(\mathrm{m}^{2} / \mathrm{s}\right)$ of nanofluids. They compared the theoretical values of Nusselt number with experimental data of water based $\mathrm{Al}_{2} \mathrm{O}_{3}$ nanofluid for a maximum volume concentration of $0.5 \%$. The analysis has been extended to $4 \% \mathrm{vol}$. concentration by Sharma et al. [13], . A good agreement of the numerical results with the experimental data have been reported. The numerical values of temperature gradients at the wall determined are reported to be inversely proportional to nanoparticle density for water based nanofluids.

The determination of nanofluid heat transfer coefficient in base liquid EG-water mixture of 60:40 ratio is mostly undertaken through experiments. The heat transfer enhancement reported by Vajjha et al. [11] is $82 \%$ with $\mathrm{Al}_{2} \mathrm{O}_{3}$ nanofluid while Kulkarni et al. [10] reported only $16 \%$ with $\mathrm{SiO}_{2}$ nanofluid at the same volume concentration of $10 \%$. The reason for the deviation in heat transfer enhancement with $\mathrm{Al}_{2} \mathrm{O}_{3}$ and $\mathrm{SiO}_{2}$ nanofluids has not been explained by the authors in the turbulent range and hence numerical analysis is undertaken in the turbulent range of Reynolds number for EG-water mixtures of 60:40 ratio. The characteristics of $\mathrm{SiO}_{2}$ nanofluid flow and heat transfer employing the van Driest eddy diffusivity equation is undertaken to determine the influence of properties on heat transfer coefficient. Only Salient result from the numerical analysis is presented.

\section{Base fluid and nanofluid properties}

The properties such as density, specific heat, viscosity and thermal conductivity of EG-W mixture were developed through regression equations employing experimental data available in the literature [14]. The properties of the base liquid are estimated with the regression equations in the numerical analysis and are given in Eqs. (4)- (7) by Sharma et al. [15]. Nanofluid properties are required for the estimation of heat transfer coefficients and friction factor. The nanofluid properties such as density and specific heat are well known conventional mixture relation and are given by Pak and Cho [16]. The thermal conductivity and viscosity of EG-water based $\mathrm{CuO}, \mathrm{Al}_{2} \mathrm{O}_{3}$ and $\mathrm{SiO}_{2}$ nanofluids are developed for different 
particle sizes, temperatures and concentration that are available in the literature [4]. The data available from experimental results of literature are used in the development of Eqs. for viscosity and thermal conductivity through regression analysis using numerical program and are given by Sharma et al. [15] in eqs (14) and (15). The experimental heat transfer coefficients of nanoparticles dispersed in base liquid EG-water mixture in 60:40 ratio by Vajjha and Das [11] is used to develop a regression equation resulting in Eq. (1)

$$
\mathrm{Nu}=0.0257 \mathrm{Re}^{0.8} \operatorname{Pr}_{\mathrm{bf}}^{0.4}\left(1+\operatorname{Pr}_{\mathrm{nf}}\right)^{-0.04297}\left(1+\frac{\emptyset}{100}\right)^{5.205}
$$

Where $\mathrm{Nu}$, Re are Nusselt number and Reynolds number respectively and $\operatorname{Pr}_{\mathrm{bf}}$ and $\operatorname{Pr}_{\mathrm{nf}}$ are prandtl number of base fluid and nanofluid respectively.

The Eq. (1) is developed with an average deviation of $7.8 \%$ and a standard deviation of $9.3 \%$ with the exception of a few data points deviating from the correlation equation by $18 \%$. The equation is valid in the temperature range of $20-90^{\circ} \mathrm{C}$ for a maximum concentration of $4 \%$ for particle diameters lower than $53 \mathrm{~nm}$. It can be observed that the substitution of $\varnothing=$ 0 and $P r_{n f}=0$ in Eq. (1) simplifies to

$$
\mathrm{Nu}=0.0257 \mathrm{Re}^{0.8} \operatorname{Pr}_{\mathrm{bf}}^{0.4}
$$

which is the conventional Dittus-Boelter equation applicable for pure fluids with a deviation of $11 \%$.

\section{Results and discussions}

The base liquid and nanofluid properties, heat transfer coefficients are validated with the experimental data. The experimental data of base liquid and $\mathrm{SiO}_{2} / \mathrm{EG}-\mathrm{W}$ nanofluid thermal conductivity are compared with Eqs. (6) and (15) of Sharma et al. [15] respectively. The thermal conductivity data is plotted in Fig. 1 for two concentrations. The results show a satisfactory agreement with a maximum deviation of $7 \%$ among all the concentrations.

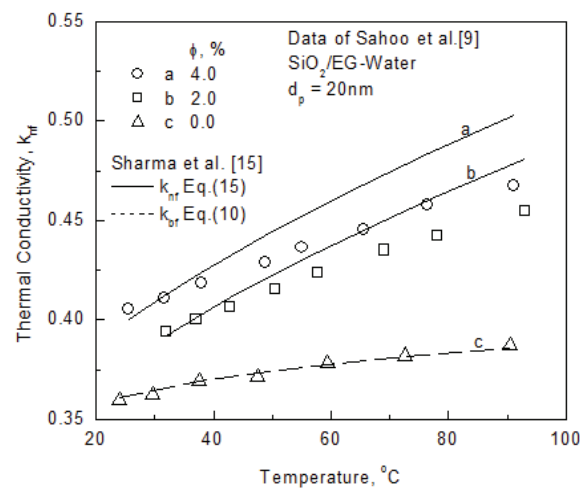

Fig.1 Comparison of thermal conductivity data with theory

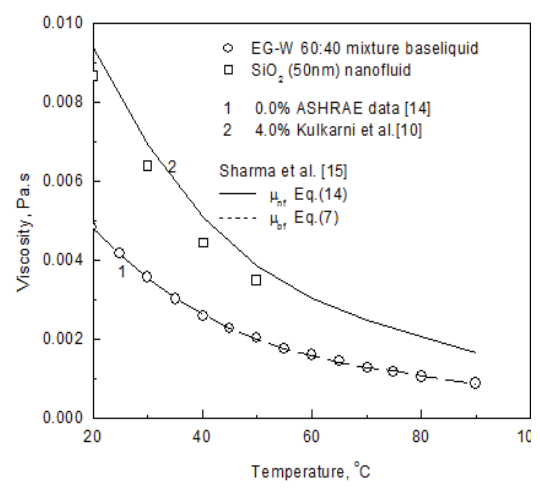

Fig. 2 Comparison of viscosity data with theory

The values of viscosity estimated with Eqs. (7) and (14) given by Sharma [15] for base liquid and nanofluid respectively are in good agreement with the experimental data with a maximum deviation of $14 \%$ among all concentrations, shown plotted in Fig.2. The experimental determination of heat transfer coefficients with base liquid EG-water 60:40 mixture were performed by Kulkarni et al.[10] and Vajjha et al. [11] in the turbulent range 
of Reynolds Number at unspecified temperatures. The temperatures are predicted using the theoretical results which is observed to be in agreement with the base liquid experimental ata at $30^{\circ} \mathrm{C}$ and $70^{\circ} \mathrm{C}$ for Kulkarni et al.[10] and Vajjha et al. [11] with a maximum deviation of $20 \%$ and $15 \%$ respectively as shown plotted in Fig. 3 .

Thus, the base liquid temperatures determined, the nanofluid heat transfer coefficient at different Reynolds number for 2 and 4\% concentration are shown plotted in Fig.4. The numerical results employing the property relations indicate that the experiments could have been undertaken at $30^{\circ} \mathrm{C}$ and $70^{\circ} \mathrm{C}$ by Kulkarni et al. [10] and Vajjha et al. [11] respectively.

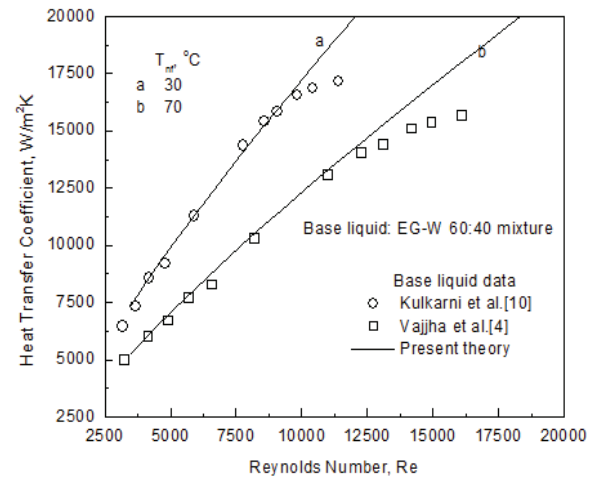

Fig.3 Comparison of base fluid heat transfer coefficient with theoretical results

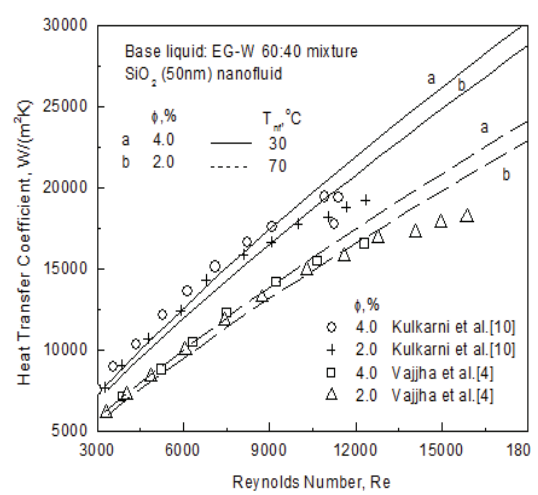

Fig.4 The variation of heat transfer coefficients with Reynolds number

It can be observed that the theoretical results are in close agreement with the experimental data with Eqs. (4)- (7) and (12)-(15) given by sharma et al. [15] are employed in the theoretical model. The concentration at which maximum heat transfer enhancement is possible can be determined with Enhancement Ratio (ER). The ER is defined as the ratio of enhancement in viscosity to that of thermal conductivity given in Eq. (21) of Sharma et a. [15].

The variation of nanofluid concentration with temperature for maximum heat transfer enhancement at various operating temperatures are shown plotted in Fig. 5 for laminar and turbulent flow conditions. From Fig.5, it is evident that at $30^{\circ} \mathrm{C}$, heat transfer enhancement for $\mathrm{SiO}_{2}$ nanofluid is not attainable for concentrations greater than $1 \%$. For experiments undertaken at $70^{\circ} \mathrm{C}$, Fig. 5 indicates heat transfer enhancements can be obtained up to $5 \%$ volume concentration under turbulent flow conditions.

The influence of particle properties on heat transfer coefficients is undertaken by a comparison of the temperature gradients rawn for $\mathrm{SiO}_{2}, \mathrm{Al}_{2} \mathrm{O}_{3}$ and $\mathrm{CuO}$ nanofluids shown plotted in Fig. 6 with Reynolds number. It can be observed that the temperature gradients decrease with increase in operating temperature which is reflected in lower values of heat transfer coefficients obtained at higher temperatures. Further, the thermal conductivity of $\mathrm{CuO}$ is greater than $\mathrm{SiO}_{2}$ nanoparticle. It is generally expected that $\mathrm{CuO}$ nanofluid to predict higher heat transfer coefficients compared to $\mathrm{SiO}_{2}$ nanofluids. However, the temperature gradient decrease with increase in nanoparticle density of $\mathrm{SiO}_{2}\left(2220 \mathrm{~kg} / \mathrm{m}^{3}\right)$ to $\mathrm{CuO}$ $\left(6900 \mathrm{~kg} / \mathrm{m}^{3}\right)$. Similar observation was reported for water based nanofluids [17]. Further studies are undertaken in this regard to determine the flow and heat transfe characteristics. 


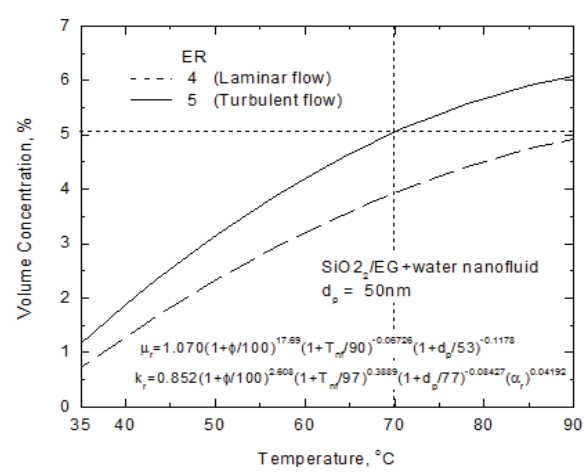

Fig.5 Evaluation of concentration for optimum heat transfer coefficient of $\mathrm{SiO}_{2}$ nanofluid at different temperatures

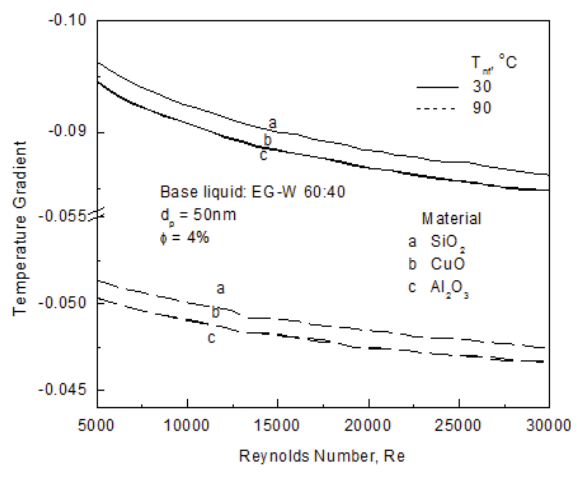

Fig. 6 Variation of temperature gradient with Reynolds number for different nanofluids

\section{Conclusions}

The salient observations from the numerical results on the nanofluid properties and heat transfer coefficients can be listed as:

(i) The proposed correlations of nanofluid viscosity and thermal conductivity can predict heat transfer coefficients satisfactorily with a maximum deviation of 7 and $14 \%$ respectively.

(ii) The Enhancement Ratio predicts an increase in heat transfer coefficient for nanofluid concentration up to $5 \%$ under turbulent flow and $4 \%$ for laminar region at an operating temperature of $70^{\circ} \mathrm{C}$.

(iii) The increase in Nusselt number of $\mathrm{SiO}_{2}$ nanofluid with concentration is not significant.

(iv) Higher heat transfer coefficients can be expected with $\mathrm{SiO}_{2}$ in comparison with $\mathrm{CuO}$ nanofluid, based on the temperature gradients obtained.

(v) $\mathrm{SiO}_{2}$ nanofluids predicts a higher temperature gradient when compared to $\mathrm{Al}_{2} \mathrm{O}_{3}$ and $\mathrm{CuO}$ based nanolfuids.

The authors acknowledge the financial assistance from Department of Mechanical Engineering, Universiti Teknologi PETRONAS, Malaysia.

\section{References}

1. A. S Ahuja, J of App Phy, 46(8): p. 3408-3416 (1975).

2. A. E. Bergles, A. E., Techniques to augment heat transfer, in Handbook of heat transfer applications, p. 31-380 (1985).

3. R. Vajjha, D. Das, and B. Mahagaonkar, PETROL SCI TECHNOL, 27(6): p. 612624 (2009).

4. R. S Vajjha, and D. K. Das, Int J Heat Mass Transf,. 52(21): p. 4675-4682 (2009).

5. R. S. Vajjha, and D. K. Das, J. Heat Transfer, 131(7): p. 071601-071601 (2009).

6. P. K. Namburu, D. P. Kulkarni, D. Misra, and D. K. Das, Exp. Therm Fluid Sci. 32(2): p. 397-402 (2007).

7. L. S. Sundar, L. S., M. K. Singh, E. V. Ramana, B. Singh, J. Grácio, and A. C. M. Sousa,. Sci. Rep. 4 (2014). 
8. B. C. Sahoo, D. K. Das, R. S. Vajjha, and J. R. Satti, J Nanotechnol Eng Med. 3(4): p. 041006 (2012).

9. B. C Sahoo, R. S. Vajjha, R. Ganguli, G. A. Chukwu, and D. K. Das, PETROL SCI TECHNOL, 27(15): p. 1757-1770 (2009).

10. D. P. Kulkarni, P. K. Namburu, H. Ed Bargar, and D. K. Das, HTrEn,. 29(12): p. 1027-1035 (2008).

11. R. S. Vajjha, D. K. Das, and D. P. Kulkarni,. Int J Heat Mass Transf,. 53(21-22): p. 4607-4618 (2010).

12. P. K. Sarma, Chada, K. V. Sharma, L. S. Sundar, P. S. Kishore, and V. Srinivas, IJHT, 28. (2010).

13. K. V. Sharma, W. H. Azmi, S. Kamal, and S. Hassan. Appl Mech Mater.. Trans Tech Publ (2016).

14. ASHRAE, Handbook of fundamentals. American Society of Heating Refrigerating and Air Conditioning Engineers, Atlanta, GA, (2005).

15. K. V. Sharma, S. K. Vandrangi, K. Habib, and S. Kamal, IJSER..7(6) (2016)

16. B. C. Pak and Y. I. Cho, EXP HEAT TRANSFER,. 11(2): p. 151-170(1998).

17. K. V. Sharma, W. Azmi, S. Kamal, P. Sarma, and B. Vijayalakshmi, Can. J. Chem. Eng., (2015). 